medRxiv preprint doi: https://doi.org/10.1101/2022.01.28.22269989; this version posted January 30, 2022. The copyright holder for this preprint (which was not certified by peer review) is the author/funder, who has granted medRxiv a license to display the preprint in perpetuity.

It is made available under a CC-BY 4.0 International license.

\title{
Three-Dimensional Cephalometric Landmarking and Analysis of Craniomaxillofacial CT scans via Deep Learning
}

\author{
Gauthier Dot ${ }^{1,2 *}$, Thomas Schouman ${ }^{1,3}$, Shaole Chang ${ }^{1}$, Frédéric Rafflenbeul ${ }^{4}$, Adeline Kerbrat ${ }^{1}$, \\ Philippe Rouch ${ }^{1,5}$, Laurent Gajny ${ }^{1}$ \\ 1 Institut de Biomecanique Humaine Georges Charpak, Arts et Metiers Paristech, Paris, France ; \\ 2 Universite de Paris, AP-HP, Hopital Pitie-Salpetriere, Service d'Odontologie, Paris, France ; \\ ${ }^{3}$ Medecine Sorbonne Universite, AP-HP, Hopital Pitie-Salpetriere, Service de Chirurgie Maxillo-Faciale, Paris, France ; \\ ${ }^{4}$ Department of Dentofacial Orthopedics, Faculty of Dental Surgery, Strasbourg University, Strasbourg, France; \\ ${ }^{5}$ EPF, Graduate School of Engineering, Cachan, France. \\ * Corresponding author
}

\section{Abstract}

The increasing use of three-dimensional (3D) imaging by orthodontists and maxillofacial surgeons to assess complex dentofacial deformities and plan orthognathic surgeries implies a critical need for 3D cephalometric analysis. Although promising methods were suggested to localize 3D landmarks automatically, concerns about robustness and generalizability restrain their clinical use. Consequently, highly trained operators remain needed to perform tedious manual landmarking. In this study, we aimed to train and evaluate a deep learning (DL) pipeline based on SpatialConfiguration-Net for automatic localization of 3D cephalometric landmarks on computed tomography (CT) scans. A retrospective sample of consecutive presurgical CT scans was randomly distributed between a training/validation set $(n=160)$ and a test set $(n=38)$. The reference data consisted in 33 landmarks, manually localized once by 1 operator $(n=178)$ or twice by 3 operators ( $n=20$, test set only). After inference on the test set, one CT scan showed "very low" confidence level predictions; we excluded it from the overall analysis but still assessed and discussed the corresponding results. The model performance was evaluated by comparing the predictions with the reference data; the outcome set included localization accuracy, cephalometric measurements and comparison to manual landmarking reproducibility. On the hold-out test set, the mean localization error was $1.0 \pm 1.3 \mathrm{~mm}$, while success detection rates for $2.0,2.5$ and $3.0 \mathrm{~mm}$ were $90.4 \%, 93.6 \%$ and $95.4 \%$, respectively. Mean errors were $-0.3 \pm 1.3^{\circ}$ and $-0.1 \pm 0.7 \mathrm{~mm}$ for angular and linear measurements, respectively. When compared to manual reproducibility, the measurements were within the Bland-Altman 95\% limits of agreement for 91.9\% and $71.8 \%$ of skeletal and dentoalveolar variables, respectively. To conclude, while our DL method still requires improvement, it provided highly accurate 3D landmark localization on a challenging test set, with a reliability for skeletal evaluation on par with what clinicians obtain. NOTE: This preprint reports new research that has not been certified by peer review and should not be used to guide clinical practice. 
medRxiv preprint doi: https://doi.org/10.1101/2022.01.28.22269989; this version posted January 30, 2022. The copyright holder for this preprint (which was not certified by peer review) is the author/funder, who has granted medRxiv a license to display the preprint in It is made available under a CC-BY 4.0 International license.

Keywords: Orthodontics; Orthognathic Surgery; Surgery, Computer-Assisted; Artificial Intelligence; Tomography, X-ray Computed; Cephalometry; Anatomic Landmarks

\section{Introduction}

Three-dimensional (3D) computed tomography (CT) or cone beam CT (CBCT) scans are increasingly used by orthodontists and maxillofacial surgeons for diagnosis and treatment planning purposes. While two-dimensional (2D) radiographs are still sufficient for most of orthodontic patients, 3D scans allow clinicians to assess complex maxillomandibular deformities and craniofacial anomalies, improving diagnosis and treatment planning for those patients (American Academy of Oral and Maxillofacial Radiology 2013; Kapila and Nervina 2015). More specifically, 3D images are now widely used for the planning of computer-assisted orthognathic surgical procedures (Alkhayer et al. 2020). For each patient, this planning is usually performed by a technician, following a surgeon's prescription based on clinical examination and cephalometric analysis of the 3D scans (Xia et al. 2009). Cephalometric analysis is used to measure the deviation of the skeletal and dentoalveolar parts of the maxilla and the mandible in relation to the skull base, using measurements between specific landmarks placed on each of these structures. The reference method for 3D cephalometric analysis is manual landmarking, which requires around 15 minutes for a highly experienced and trained operator (Hassan et al. 2013; Dot et al. 2021).

The automatization of 3D cephalometric landmarking has been an active research field over the last decade, as the clinical dissemination of such a method would decrease the burden of manual landmarking. Two systematic reviews recently reported on the accuracy of such automated methods (Dot et al. 2020; Schwendicke, Chaurasia, et al. 2021). Both yielded promising results for deep learning (DL) based methods, which outperformed previously-proposed knowledge-based, atlas-based or shallow learning-based methods. DL methods published in the last few years can localize 3D cephalometric landmarks with great accuracy, often under the 2-mm threshold of clinical acceptability (Lee et al. 2019; O'Neil et al. 2019; Torosdagli et al. 2019; Lang et al. 2020; Ma et al. 2020; Yun et al. 2020; Zhang et al. 2020; Bermejo et al. 2021; Chen et al. 2021; Kang et al. 2021; Liu et al. 2021; Chen et al. 2022). The studies showing the best results usually formulate landmark detection as a regression problem, using landmark heatmap regression methods (Zhang et al. 2020; Chen et al. 2021). However, the evaluation of the published models is often limited to few landmarks, and both systematic reviews noted a high risk of bias in the reporting of these studies, mainly because the description of the database/reference was limited and because the accuracy scores were calculated from within-sample validation datasets or very small hold-out test sets (<10 scans). As a result, major concerns remain about the robustness and generalizability of DL methods for 3D cephalometric landmarking, 
medRxiv preprint doi: https://doi.org/10.1101/2022.01.28.22269989; this version posted January 30, 2022. The copyright holder for this preprint (which was not certified by peer review) is the author/funder, who has granted medRxiv a license to display the preprint in

It is made available under a CC-BY 4.0 International license.

highlighting the need for additional evaluation studies with clinically-relevant datasets, clear reference data and broader outcome metrics (Dot et al. 2020; Schwendicke, Chaurasia, et al. 2021).

Recently, the fully convolutional neural network (CNN) SpatialConfiguration-Net (SCN) was proposed as a heatmap regression method integrating a spatial configuration module for landmark localization (Payer et al. 2019). SCN has shown impressive results for the localization of anatomic landmarks on datasets of hand radiographs, lateral cephalograms and spine CT scans, but has yet to be evaluated on craniomaxillofacial CT scans (Payer et al. 2019; Sekuboyina et al. 2021). One difficulty to overcome is data size, as high resolution Head CT scans exceed the memory capacity of a typical graphical processing unit (GPU). There are two solutions to overcome this obstacle: 1 ) downsampling the scans by decreasing their resolution; 2) implementing the CNNs on small 3D image patches. However, downsampled data necessarily result in less accurate landmark localization, while image patches oftentimes lack volumetric context. But a 2-step, coarse-to-fine approach combining both methods could overcome these limitations (Chen et al. 2021; Sekuboyina et al. 2021).

The main goal of this study was to design and implement a coarse-to-fine DL method based on SCN for automatic landmark localization, before thoroughly evaluating its performance with a set of 33 landmarks on a hold-out test dataset of craniomaxillofacial CT scans from clinical practice.

\section{Materials and Methods}

A DL pipeline was followed to localize cephalometric landmarks automatically on randomly selected craniomaxillofacial CT scans. We compared the results of our DL-based method on a hold-out test dataset (the index test) with those obtained by manual landmarking (the reference test). Our outcome set included localization accuracy, cephalometric measurements and comparison to manual landmarking reproducibility. This study was approved by an appropriate Institutional Review Board (IRB No. CRM-2001-051) and its reporting followed recently published recommendations on artificial intelligence in dental research (Schwendicke, Singh, et al. 2021).

\section{Dataset}

Two hundred randomly-selected presurgical CT scans were obtained from a retrospective sample of consecutive patients having undergone orthognathic surgery in a single maxillofacial surgery department described in a previous study (Dot et al. 2022 Jan 17). Two subjects refused to participate; their data was excluded from the dataset. 198 subjects (198 anonymized presurgical CT scans) were eventually included in our dataset and randomly distributed among a training set $(n=128)$, a validation set $(n=32)$ and a test set $(n=38)$ (Appendix Figure 1$)$. CT scans and patient characteristics are detailed in Appendix Table 1. 
medRxiv preprint doi: https://doi.org/10.1101/2022.01.28.22269989; this version posted January 30, 2022. The copyright holder for this preprint (which was not certified by peer review) is the author/funder, who has granted medRxiv a license to display the preprint in It is made available under a CC-BY 4.0 International license.

\section{Manual Landmarking (Reference Test)}

Thirty-three landmarks, divided into skeletal $(n=21)$ and dental $(n=12)$ landmarks (Fig. 1A), were manually annotated on each CT scan, either once $(n=178$ ) by operator \#1 (a trained orthodontist with 5 years of clinical experience), or twice ( $n=20$ ) by operators \#1, \#2 (a trained orthodontist with 5 years of clinical experience) and \#3 (a final year postgraduate maxillofacial surgeon). The reference data used to train and test our DL model were either the single annotations $(n=178)$ or the means of the 6 annotations ( $n=20$, test set only). The scans annotated six times were part of a previous repeatability and reproducibility (R\&R) study (Dot et al. 2021). Landmark definitions and landmarking procedure are detailed in the appendix.

\section{Deep Learning-Based Landmarking (Index Test)}

The DL model implemented in this study was the SCN described by Payer et al. (Payer et al. 2019). The pipeline used to train the network followed a coarse-to-fine approach: 1) to keep most of the volumetric context, we trained a first network (SCN\#1) on downsampled-resolution full scans; 2) to localize the landmarks more accurately within selected regions of interest (ROIs), five networks (SCN\#2 to SCN\#6) were trained on selected full-resolution ROIs (Fig. 1B). The coordinates of each local heatmap maxima were considered as the predicted landmark positions. The confidence in a network prediction was evaluated as "very low" when the heatmap maximum value was below a threshold established from the validation results. Please refer to the appendix for additional implementation details.

Inference (prediction made by the trained model) was performed on our hold-out test set ( $n=38$ ) following a 2-stage method (Fig. 1B). At stage 1, SCN\#1 predicted the "coarse" localization of the landmarks, which was then used to extract the 5 ROIs. At stage 2, SCN\#2 to SCN\#6 predicted the "fine" localization of the landmarks in each ROI along with the confidence in the prediction. This method systematically localized 33 landmarks for each CT scan. In CT scans with missing landmarks (i.e. missing teeth), the corresponding predictions were considered as missing values and deleted by the operator.

\section{Evaluation}

\section{Outlier cases}

Subjects with several "very low" confidence levels in coordinate predictions were considered as outlier cases. They were not taken into account for the overall evaluation of the network, but individual localization performance was nonetheless assessed and discussed. 
medRxiv preprint doi: https://doi.org/10.1101/2022.01.28.22269989; this version posted January 30, 2022. The copyright holder for this preprint (which was not certified by peer review) is the author/funder, who has granted medRxiv a license to display the preprint in perpetuity.

It is made available under a CC-BY 4.0 International license .

\section{Localization performance}

To evaluate the overall localization performance on our test set, three commonly-used criteria were computed for each landmark (Wang et al. 2016): 1) mean radial error (MRE) - mean Euclidian distance between the reference landmark and the predicted landmark \pm its standard deviation; 2) success detection rate $(S D R)$ - proportion of landmarks located with radial errors under $2 \mathrm{~mm}, 2.5 \mathrm{~mm}, 3 \mathrm{~mm}$; 3) minimum and maximum radial error. Each landmark was subjected to statistical analysis to compare the errors obtained from scans with reference constructed from 1 annotation with the errors obtained from scans with reference constructed from means of 6 annotations.
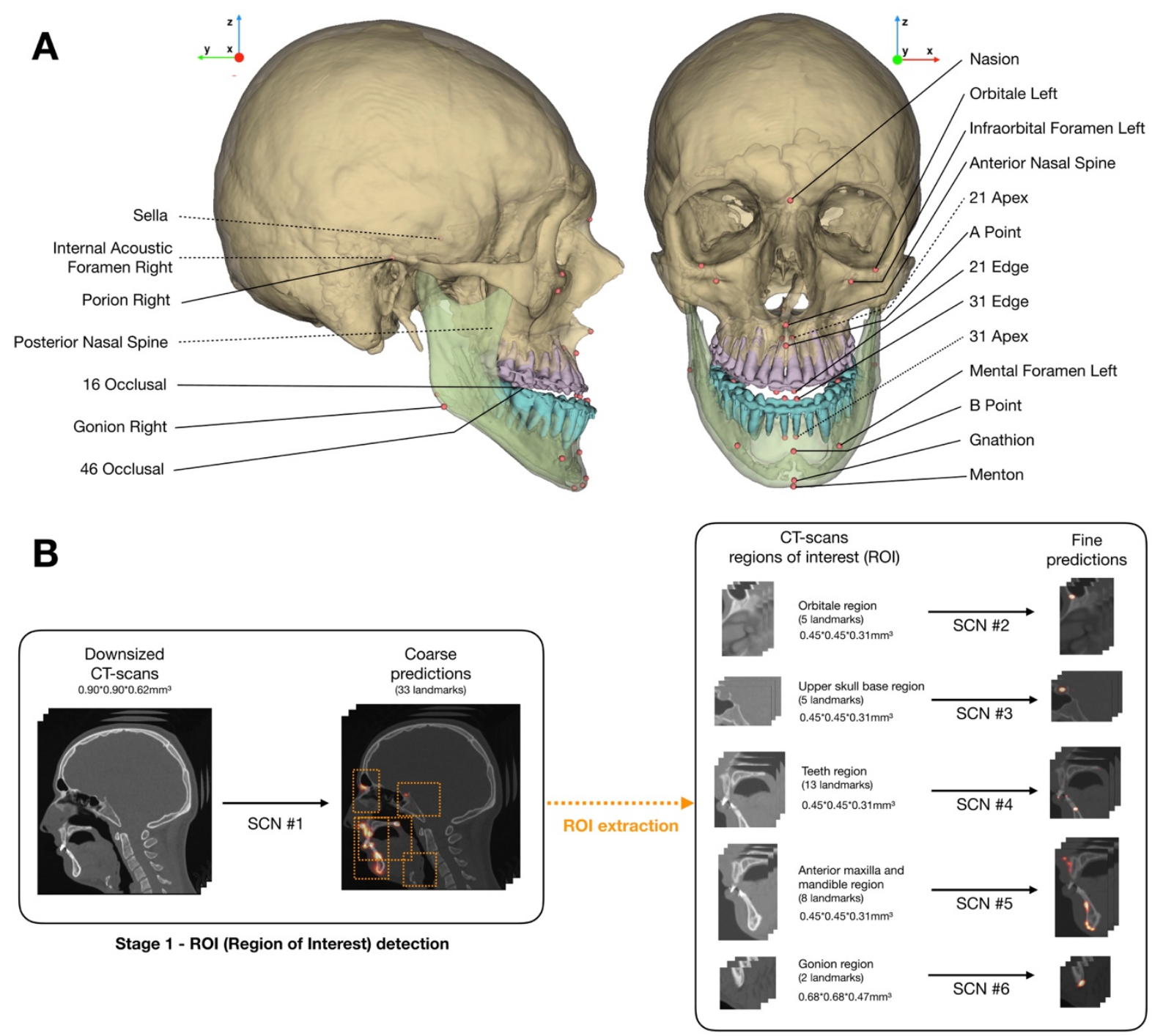

Stage 2 - Fine landmark detection

Figure 1. Landmarks and pipeline of the deep learning model. (A) Illustration of the set of 33 landmarks; bilateral landmarks are named once; dotted lines show landmarks localized inside the skull; (B) 2-stage method used for model inference. SCN, SpatialConfiguration-Net; ROI, region of interest. 
medRxiv preprint doi: https://doi.org/10.1101/2022.01.28.22269989; this version posted January 30, 2022. The copyright holder for this preprint (which was not certified by peer review) is the author/funder, who has granted medRxiv a license to display the preprint in It is made available under a CC-BY 4.0 International license.

\section{Cephalometric Measurements}

A conventional cephalometric analysis (Appendix Table 4) was conducted; nine 2D angles (degrees) and six 2D distances $(\mathrm{mm})$ were calculated using orthogonal projections of the 3D landmarks on an automatically constructed midsagittal plane (MSP). MSP construction followed two steps: 1) the CT scans were segmented using a previously published DL-based automated method (Dot et al. 2022 Jan 17); 2) the MSP was computed thanks to the upper skull segmentation using a previously published automated method (Pinheiro et al. 2019). For each variable and each CT scan, the difference between the measurements obtained from reference landmarks and from predicted landmarks was computed and the proportion of measurements with differences under $2 \mathrm{~mm}$ or $2^{\circ}$ was calculated. Additionally, the accuracy of Frankfort horizontal (FH) plane construction (porion right/left and orbitale left) was evaluated by computing the absolute angular distances between reference and predicted FH planes.

\section{Comparison with manual landmarking reproducibility}

The results from a previous R\&R study were used to assess the Bland-Altman $95 \%$ limits of agreement (LOA) of manual landmarking reproducibility (Dot et al. 2021). The proportion of predicted landmarks within these limits was computed for each $-x-y-z$ axis. In addition, we applied ISO norm 5725 on the cephalometric variables to calculate the $95 \%$ LoA of manual measurement reproducibility (Appendix Table 5) (ISO 5725-2:2019). The proportion of predicted cephalometric variables within these limits was computed. For the CT scans included in the R\&R study, statistical tests were used to compare automatic and manual results, and boxplots of the localization and measurement errors were computed.

\section{Statistical analysis}

Continuous variables were presented as means \pm standard deviations; categorical variables were expressed as numbers and percentages. We used Wilcoxon and Student t-tests for nonparametric and parametric data, respectively; $p$-values $<0.05$ were considered statistically significant.

\section{Results}

\section{Training, testing and outlier case}

Training time for one network on one GPU was about 48 hours (see implementation details in the appendix). Inference required around 1 minute per CT scan. One CT scan from a patient exhibiting cleidocranial dysplasia showed several predictions (A Point and several dental landmarks) with "very low" confidence levels. It was therefore considered as an outlier case and was excluded from the overall analysis, although individual localization performance was assessed and discussed. 
medRxiv preprint doi: https://doi.org/10.1101/2022.01.28.22269989; this version posted January 30, 2022. The copyright holder for this preprint (which was not certified by peer review) is the author/funder, who has granted medRxiv a license to display the preprint in perpetuity.

It is made available under a CC-BY 4.0 International license.

\section{Localization performance}

On our test set without the outlier case $(n=37)$, MRE for all landmarks was $1.0 \mathrm{~mm} \pm 1.3 \mathrm{~mm}$ and SDRs for all landmarks were $90.4 \%, 93.6 \%$ and $95.4 \%$, using $2 \mathrm{~mm}, 2.5 \mathrm{~mm}$ and $3 \mathrm{~mm}$ precision ranges, respectively. Thirteen landmarks (39.4\%) showed SDRs at $2 \mathrm{~mm}$ of $100 \%$; 24 landmarks (72.7\%) showed SDRs at $2 \mathrm{~mm}$ over $90 \%$, and 5 landmarks (15.2\%) showed SDRs at $2 \mathrm{~mm}$ under $80 \%$ (B point, gonion left and right, orbitale left and right). Individual MRE and SDR results for each landmark are shown in Table 1. Appendix Tables 6, 7 and 8 respectively show the results on the test set with the outlier case included, the individual radial errors for the outlier case and the results for the validation set. When comparing scans with references constructed from 1 or 6 annotations, there were no statistically significant differences in radial errors except for 3 landmarks: orbitale left, 11 incisal edge and 41 incisal edge.

Table 1. Mean radial errors $(\mathrm{mm})$, success detection rates $(\%(n))$ and minimum/maximum radial error $(\mathrm{mm})$ for each landmark on the hold-out test set without the outlier case $(n=37)$. MRE, mean radial error; SD, standard deviation; Min., minimum radial error; Max., maximum radial error; L, left; $R$, right.

\begin{tabular}{|c|c|c|c|c|c|c|}
\hline & MRE $\pm S D$ & $<2 \mathrm{~mm}$ & $<2.5 \mathrm{~mm}$ & $<3 \mathrm{~mm}$ & Min. & Max. \\
\hline 11 Apex & $0.7 \pm 0.4$ & $100(37)$ & 100 (37) & $100(37)$ & 0.2 & 1.5 \\
\hline 11 Edge & $0.4 \pm 0.3$ & $100(37)$ & 100 (37) & $100(37)$ & 0.1 & 1.3 \\
\hline 16 Occlusal & $1.3 \pm 2.4$ & $94.4(34)$ & $94.4(34)$ & 94.4 (34) & 0.1 & 11.2 \\
\hline 21 Apex & $0.7 \pm 0.3$ & $100(37)$ & $100(37)$ & $100(37)$ & 0.2 & 1.9 \\
\hline 21 Edge & $0.5 \pm 0.3$ & $100(37)$ & $100(37)$ & $100(37)$ & 0.1 & 1.4 \\
\hline 26 Occlusal & $1.2 \pm 2.4$ & $94.4(34)$ & $94.4(34)$ & $94.4(34)$ & 0.1 & 11.4 \\
\hline 31 Apex & $0.9 \pm 1.4$ & $97.1(34)$ & $97.1(34)$ & $97.1(34)$ & 0.2 & 8.7 \\
\hline 31 Edge & $0.6 \pm 1.1$ & $94.4(33)$ & $97.1(34)$ & $97.1(34)$ & 0.1 & 6.7 \\
\hline 36 Occlusal & $1.5 \pm 2.9$ & 91.7 (33) & $91.7(33)$ & 91.7 (33) & 0.2 & 11.3 \\
\hline 41 Apex & $0.6 \pm 0.3$ & $100(37)$ & 100 (37) & $100(37)$ & 0.2 & 1.3 \\
\hline 41 Edge & $0.5 \pm 0.2$ & $100(37)$ & 100 (37) & $100(37)$ & 0.1 & 1.3 \\
\hline 46 Occlusal & $0.9 \pm 1.8$ & $97.2(35)$ & $97.2(35)$ & $97.2(35)$ & 0.6 & 11.0 \\
\hline A Point & $1.1 \pm 0.9$ & 89.2 (33) & $91.9(34)$ & 91.9 (34) & 0.2 & 3.9 \\
\hline Anterior Nasal Spine & $0.7 \pm 0.7$ & $94.6(35)$ & $94.6(35)$ & $97.3(36)$ & 0.1 & 3.2 \\
\hline B Point & $1.7 \pm 1.5$ & $67.6(25)$ & $81.1(30)$ & $91.9(34)$ & 0.3 & 8.5 \\
\hline Gnathion & $1.6 \pm 0.6$ & $91.9(34)$ & $97.3(36)$ & $100(37)$ & 0.3 & 2.5 \\
\hline Gonion L & $1.9 \pm 1.7$ & $70.3(26)$ & $75.7(28)$ & $86.5(32)$ & 0.3 & 7.3 \\
\hline Gonion R & $2.1 \pm 1.4$ & $48.7(18)$ & $70.3(26)$ & $73.0(27)$ & 0.3 & 6.9 \\
\hline Infraorbital Foramen L & $0.6 \pm 0.3$ & $100(37)$ & $100(37)$ & $100(37)$ & 0.2 & 2.0 \\
\hline Infraorbital Foramen R & $0.6 \pm 0.5$ & $97.3(36)$ & $100(37)$ & $100(37)$ & 0.1 & 2.4 \\
\hline Internal Acoustic Foramen L & $0.6 \pm 0.4$ & $100(37)$ & $100(37)$ & $100(37)$ & 0.2 & 1.9 \\
\hline Internal Acoustic Foramen R & $0.6 \pm 0.6$ & $97.3(36)$ & $97.3(36)$ & $97.3(36)$ & 0.1 & 3.9 \\
\hline Mental Foramen L & $0.4 \pm 0.2$ & $100(37)$ & $100(37)$ & $100(37)$ & 0.1 & 0.8 \\
\hline Mental Foramen R & $0.4 \pm 0.3$ & $100(37)$ & $100(37)$ & $100(37)$ & 0.1 & 1.3 \\
\hline
\end{tabular}


medRxiv preprint doi: https://doi.org/10.1101/2022.01.28.22269989; this version posted January 30, 2022. The copyright holder for this preprint (which was not certified by peer review) is the author/funder, who has granted medRxiv a license to display the preprint in perpetuity.

It is made available under a CC-BY 4.0 International license.

$\begin{array}{lllllll}\text { Menton } & 1.6 \pm 0.6 & 94.6(35) & 97.3(36) & 100(37) & 0.4 & 2.6 \\ \text { Nasion } & 0.6 \pm 0.3 & 100(37) & 100(37) & 100(37) & 0.1 & 1.9 \\ \text { Orbitale L } & 2.7 \pm 2.0 & 43.2(16) & 56.8(21) & 67.6(25) & 0.1 & 8.8 \\ \text { Orbitale R } & 2.6 \pm 2.3 & 56.8(21) & 67.6(25) & 70.3(26) & 0.3 & 9.7 \\ \text { Pogonion } & 1.1 \pm 0.6 & 89.2(33) & 97.3(36) & 100(37) & 0.2 & 3.0 \\ \text { Porion L } & 1.1 \pm 0.5 & 89.2(33) & 100(37) & 100(37) & 0.2 & 2.3 \\ \text { Porion R } & 1.3 \pm 0.7 & 86.5(32) & 89.2(33) & 100(37) & 0.3 & 2.8 \\ \text { Posterior Nasal Spine } & 0.5 \pm 0.4 & 100(37) & 100(37) & 100(37) & 0.1 & 1.5 \\ \text { Sella } & 0.8 \pm 0.4 & 100(37) & 100(37) & 100(37) & 0.2 & 2.0\end{array}$

\section{Cephalometric Analysis}

On our test set without the outlier case $(n=37)$, mean differences between the reference and predicted measurements were $-0.3 \pm 1.3^{\circ}$ for angular observations and $-0.1 \pm 0.7 \mathrm{~mm}$ for linear observations (Table 2). 96.7\% $(n=322)$ of the skeletal measurements and $83.8 \%(n=181)$ of the dentoalveolar measurements showed errors inferior to $2 \mathrm{~mm} / 2^{\circ}$. The mean absolute angular distance between predicted and reference $\mathrm{FH}$ planes was $0.4 \pm 0.3^{\circ}$, and all the measurements were inferior to $2^{\circ}$.

Table 2. Mean errors $(\mathrm{mm})$ and success detection rates $(\%(n))$ for each cephalometric variable on the hold-out test set without the outlier case $(n=37)$. SD, standard deviation.

\begin{tabular}{|c|c|c|c|}
\hline & Mean & SD & $<2 \mathrm{~mm} / 2^{\circ}$ \\
\hline \multicolumn{4}{|l|}{ Skeletal } \\
\hline SNA $\left({ }^{\circ}\right)$ & -0.1 & 0.7 & $100(37)$ \\
\hline $\operatorname{SNB}\left({ }^{\circ}\right)$ & -0.0 & 0.7 & $100(37)$ \\
\hline ANB $\left(^{\circ}\right)$ & -0.1 & 0.2 & $100(37)$ \\
\hline ANS-PNS / Go-Gn $\left({ }^{\circ}\right)$ & -0.1 & 1.3 & 91.9 (34) \\
\hline S-Na / Go-Gn $\left({ }^{\circ}\right)$ & 0.0 & 1.4 & $83.8(31)$ \\
\hline Pog to NB (mm) & 0.0 & 0.4 & $100(37)$ \\
\hline A to MSP (mm) & 0.0 & 0.3 & $100(37)$ \\
\hline B to MSP (mm) & -0.3 & 0.6 & $97.3(36)$ \\
\hline Pog to MSP (mm) & -0.2 & 0.7 & $97.3(36)$ \\
\hline \multicolumn{4}{|l|}{ Dentoalveolar } \\
\hline SN / Occlusal plane $\left({ }^{\circ}\right)$ & -0.2 & 1.2 & $97.1(34)$ \\
\hline Upper inc / ANS-PNS $\left({ }^{\circ}\right)$ & -0.8 & 1.5 & 75.7 (28) \\
\hline Upper inc to NA (mm) & 0.2 & 0.5 & $100(37)$ \\
\hline Inter-incisal angle $\left({ }^{\circ}\right)$ & -1.1 & 1.9 & $54.3(19)$ \\
\hline Lower inc / Go-Gn ( ${ }^{\circ}$ ) & -0.4 & 1.8 & $77.1(27)$ \\
\hline Lower inc to NB (mm) & -0.1 & 1.0 & $97.3(36)$ \\
\hline
\end{tabular}


medRxiv preprint doi: https://doi.org/10.1101/2022.01.28.22269989; this version posted January 30, 2022. The copyright holder for this preprint (which was not certified by peer review) is the author/funder, who has granted medRxiv a license to display the preprint in perpetuity.

It is made available under a CC-BY 4.0 International license .

\section{Comparison with manual landmarking and measurement reproducibility}

On our test set without the outlier case $(n=37)$, when comparing predicted landmark coordinates in the $-x,-y$ and $-z$ directions with manual landmarking repeatability, $90.7 \%(n=2114)$ of the skeletal coordinates and 65.4\% $(n=871)$ of the dental coordinates were within 95\% LoA (Appendix Table 9). When comparing predicted cephalometric measurement errors with manual measurement repeatability, $91.9 \%(n=306)$ of the skeletal variables and $71.8 \%(n=155)$ of the dentoalveolar variables were within 95\% LoA (Appendix Table 10). For the scans included in the R\&R study (without the outlier case, $n=19$ ), localization and measurement error boxplots for the manual and automatic methods are shown in Figure 2. The errors showed statistically significant differences (Fig. 2) for 5 skeletal landmarks (32.8\%), 10 dental landmarks (83.3\%), 1 skeletal measurement (11.1\%) and 2 dentoalveolar measurements (33.3\%).
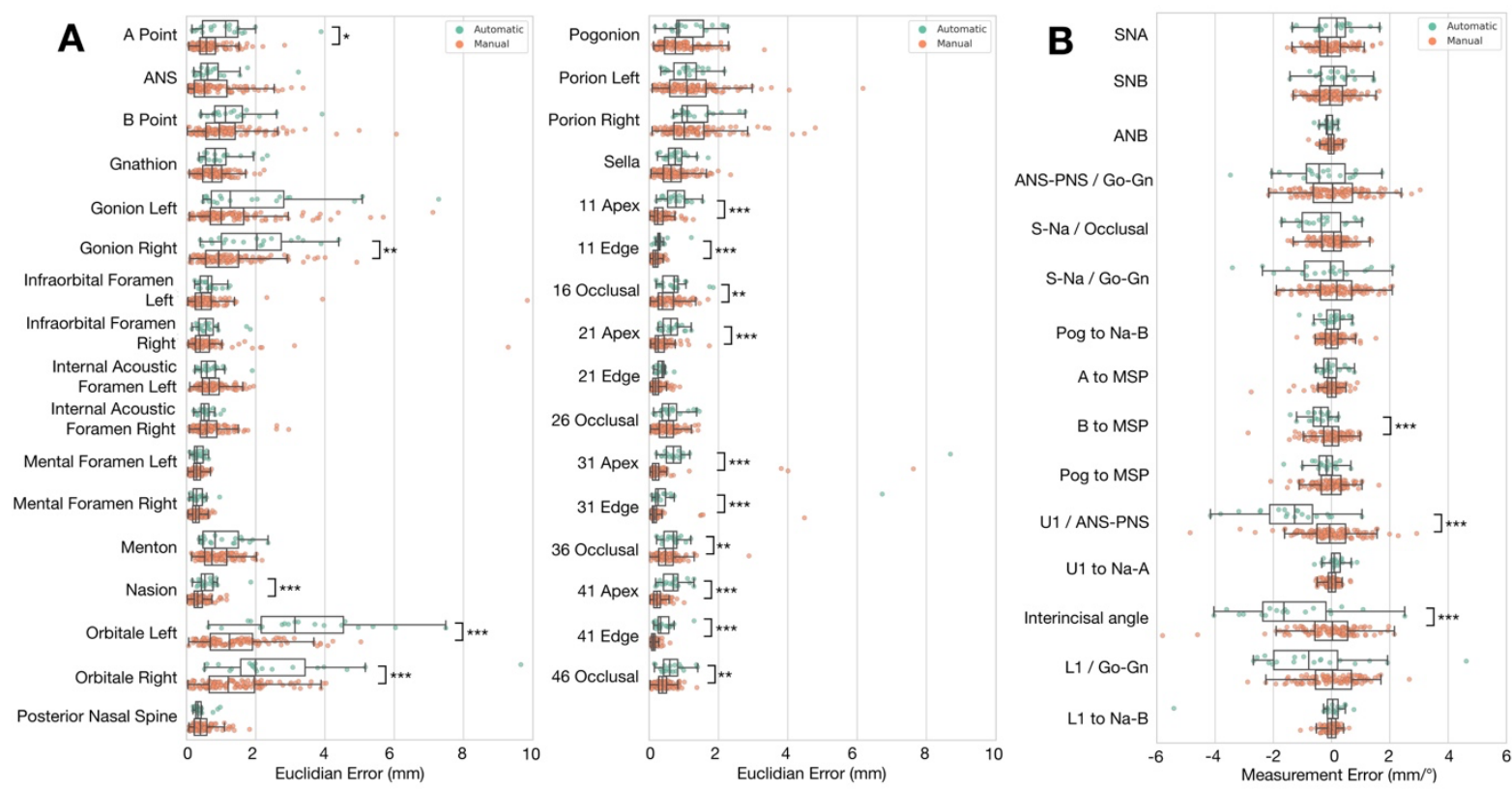

Figure 2. Localization and measurement error boxplots for automatic (green) and manual (orange) methods on $19 \mathrm{CT}$ scans from the test set. (A) Localization errors $(\mathrm{mm})$ for each landmark; (B) Measurement errors $\left(\mathrm{mm} /{ }^{\circ}\right)$ for each cephalometric variable. For each pair of results, statistically significant differences are indicated $(* p<0.05 ; * * p<0.01 ; * * * p<0.001)$.

\section{Three-Dimensional Visualization}

We chose two subjects representative of our test dataset as well as the "outlier case" to illustrate our results. Figure 3 shows reference and predicted landmarks plotted on the fully automatically-obtained CT scan segmentations (Dot et al. 2022 Jan 17). 
medRxiv preprint doi: https://doi.org/10.1101/2022.01.28.22269989; this version posted January 30, 2022. The copyright holder for this preprint (which was not certified by peer review) is the author/funder, who has granted medRxiv a license to display the preprint in perpetuity.

It is made available under a CC-BY 4.0 International license.
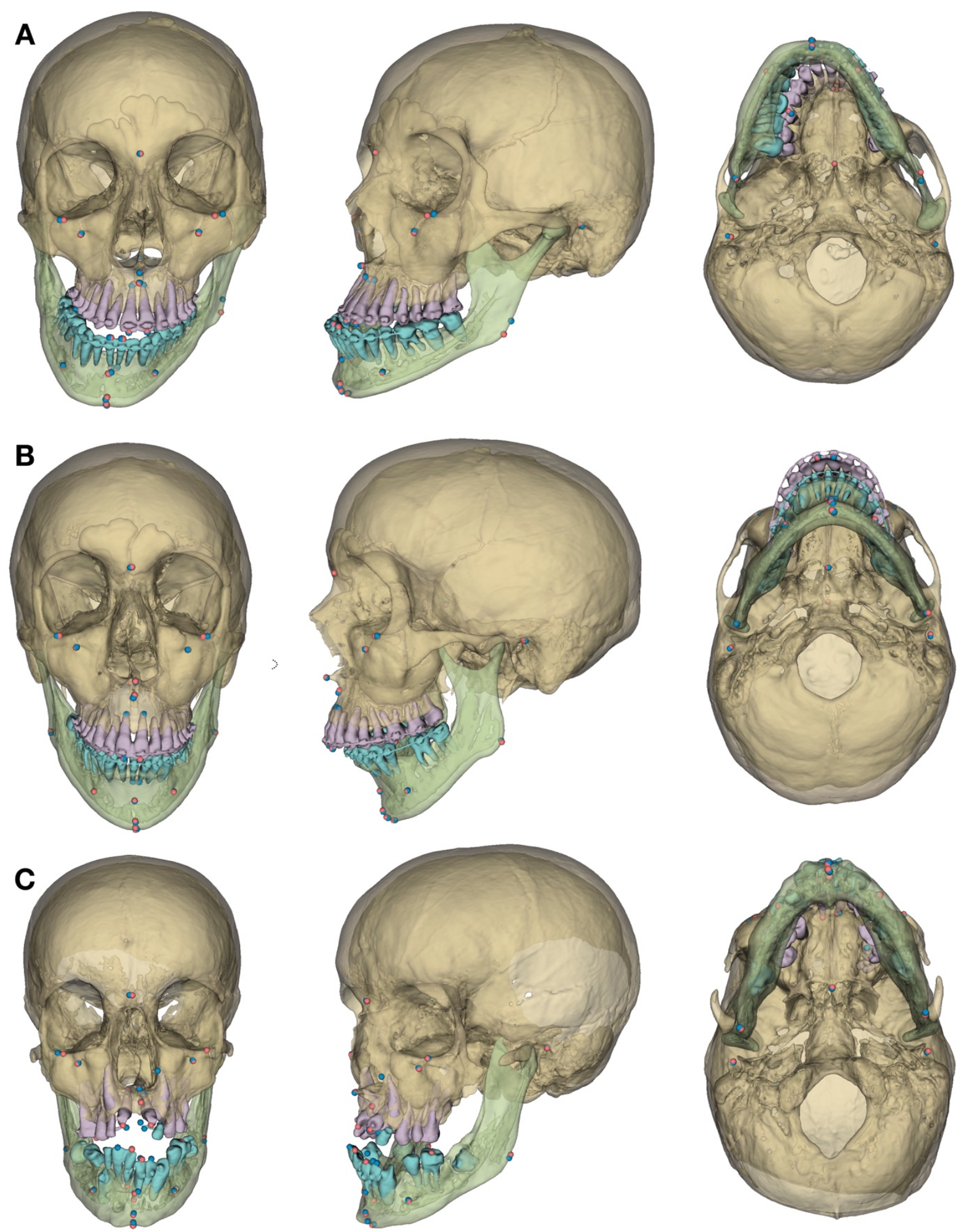

Figure 3. Frontal, $3 / 4$ left and inferior views of the 3D models, reference (red) and predicted (blue) landmarks for 3 subjects. (A) Prognathic and asymmetric mandible; (B) retrognathic mandible; (C) craniofacial syndrome "outlier case", the errors in the predicted A point (at the level of the upper left canine apex) and the dental landmarks are to be noted. 
medRxiv preprint doi: https://doi.org/10.1101/2022.01.28.22269989; this version posted January 30, 2022. The copyright holder for this preprint (which was not certified by peer review) is the author/funder, who has granted medRxiv a license to display the preprint in perpetuity.

It is made available under a CC-BY 4.0 International license.

\section{Discussion}

The increasingly common use of 3D scans to assess complex maxillomandibular deformities and to plan orthognathic surgeries implies a critical need for clinical implementation of 3D cephalometric analyses. Such analyses currently require manual localization of 3D landmarks, a task that is timeconsuming ( $\pm 15 \mathrm{mn}$ ) and demands highly trained operators. In this study, we trained a DL network in order to localize 33 cephalometric landmarks automatically before evaluating the model on a challenging hold-out test set from clinical practice. The proposed DL pipeline took around one minute to localize the landmarks in a fully automatic manner. This amounts to a significant reduction of the time and effort needed for the task. The landmarks were localized with high accuracy, with $90.4 \%$ less than $2 \mathrm{~mm}$ away from the manually localized reference landmarks.

Heterogeneity in the methods and datasets make studies reporting DL results notoriously difficult to evaluate and compare (Schwendicke, Singh, et al. 2021). The main strength of our study is that it provides a validation of our method based on a clinically-relevant test dataset, randomly selected from a clinical sample of presurgical CT scans. Moreover, we carefully constructed our reference test (manual landmarking) using the means of the six repetitions from a previously published $R \& R$ study for twenty of the test scans and asking one of this R\&R study's operators to label the 178 remaining scans. Overall, our results are comparable to current state-of-the art studies localizing landmarks on CBCT scans, some landmarks showing slightly better and other slightly worse localization results (Torosdagli et al. 2019; Zhang et al. 2020; Chen et al. 2021). However, previous studies lacked a clear definition of their dataset, localized fewer landmarks and evaluated their results following a cross-validation approach with no hold-out test dataset, which might question the generalizability of the results. It must be noted that our study focused on CT scans because it is the only imaging modality used for computer-assisted planning and personalized implant manufacturing for orthognathic surgery in our maxillofacial surgery department at this time. In future works we plan to use CBCT data in order to fine-tune our model and evaluate its accuracy on this other widespread imaging modality. Currently, our method does not perform automatic detection of the presence or absence of the landmarks; in the case of missing landmarks, those were deleted manually. We considered this approach sufficient, as it is easy for an operator to identify missing landmarks when running the cephalometric analysis, but other methods have been suggested to perform this task automatically (Lang et al. 2020; Chen et al. 2021).

The main goal of cephalometric landmarking is to perform linear and angular measurements which will ultimately provide clinical guidance. In order to evaluate the clinical usefulness of our DLbased method, our outcome set included lateral cephalometric measurements commonly found in R\&R studies (van Bunningen et al. 2021 Aug 28) as well as three additional frontal measurements. We 
medRxiv preprint doi: https://doi.org/10.1101/2022.01.28.22269989; this version posted January 30, 2022. The copyright holder for this preprint (which was not certified by peer review) is the author/funder, who has granted medRxiv a license to display the preprint in It is made available under a CC-BY 4.0 International license.

chose to perform 2D cephalometric measurements based on orthogonally projected landmarks because 3D cephalometric analysis remains complex, and thus beyond the scope of this study (Gateno et al. 2011). These measurements do not use the full potential of 3D cephalometry, but we believe they provide useful insight on the potential clinical usefulness of the method.

Concerning the skeletal landmarks, it has been shown that the reproducibility of manual landmarking was highly dependent on the type of landmark: landmarks localized on clear anatomical boundaries (e.g., sutures, spikes, holes) tend to be more reproducible than landmarks localized on skeletal contours (Sam et al. 2019). The comparison of our DL-based method with manual landmarking reproducibility shows that it is on par with trained clinicians for the localization of skeletal landmarks. Error-prone landmarks tend to be the same whether the landmarking is performed manually or automatically. Furthermore, even the landmarks with the worst accuracy results provided highly accurate cephalometric measurements or FH plane constructions, comparable with those obtained by clinicians. This confirms the need for evaluation outcomes other than MRE and SDR, as radial errors do not necessarily translate into clinically relevant errors (Gupta et al. 2016). Interestingly, landmarks localized on the craniofacial foramens showed excellent accuracy results, with 99.1\% $(n=220)$ of the landmarks located within $2 \mathrm{~mm}$ from the reference. These "novel" landmarks, which could not be localized on 2D cephalograms, could be used in future 3D cephalometric analyses (Naji et al. 2014; Lim et al. 2019; Dot et al. 2021).

Concerning the dental landmarks, despite good overall accuracy, the automated method provided less reliable results than the clinicians. The localization of these landmarks could probably be improved by refining their positions on the CT scan segmentation, for example using an additional knowledge-based method (Montúfar et al. 2018). When the patients' intraoral scans are superimposed on the CT scans, for surgery planning for instance, they may also be segmented automatically and used for refining crown landmark localization (Hao et al. 2021 Nov 1).

We excluded the subject showing several landmarks with "very low" confidence levels, because such levels usually signal that the network did not work as expected and could lead to major errors. In this case, several landmarks (A Point and dental landmarks) showed errors $>10 \mathrm{~mm}$ (Appendix Table 7) and required operator corrections. These errors are probably due to the atypical anatomy of this subject, who exhibited a rare syndromic disease with several included teeth (Fig. 3C). From a clinical viewpoint, additional verification and correction of the results could be performed on a visualization of the predicted landmarks plotted on 3D models obtained fully automatically via DL (Fig. 3) (Wang et al. 2021; Dot et al. 2022 Jan 17).

To conclude, the proposed method achieved high accuracy on a test set of presurgical CT scans, providing results on par with those of clinicians for skeletal landmark localization and subsequent cephalometric measurements. The localization of dental landmarks still requires 
medRxiv preprint doi: https://doi.org/10.1101/2022.01.28.22269989; this version posted January 30, 2022. The copyright holder for this preprint (which was not certified by peer review) is the author/funder, who has granted medRxiv a license to display the preprint in It is made available under a CC-BY 4.0 International license.

improvement to provide more reliable cephalometric measurements. Despite these promising results, our model requires additional testing in order to further evaluate its generalizability, reproducibility and robustness. The model is yet to be evaluated on an external test dataset including data from other clinical centers and CT machines. Afterwards, a prospective diagnostic efficacy study should evaluate the impact of using such an automated tool in routine clinical practice.

\section{Author Contributions}

G. Dot contributed to the conception, design, data acquisition, analysis and interpretation, performed all statistical analyses, drafted and critically revised the manuscript. T. Schouman, P. Rouch and L. Gajny contributed to the conception, design and data interpretation, and critically revised the manuscript. S. Chang, F. Rafflenbeul and A. Kerbrat contributed to the data analysis and critically revised the manuscript. All authors gave final approval and agree to be accountable for all aspects of the work.

\section{Acknowledgments}

The authors would like to thank C. Payer and all the team behind SpatialConfiguration-Net for sharing their research and codes.

\section{Declaration of Conflicting Interests}

The authors declared no potential conflicts of interest with respect to the research, authorship, and/or publication of this article.

\section{Funding}

This study has received funding by the "Fondation des Gueules Cassées" (grant number 28-2020).

\section{Ethical Approval}

The IRB “Comité d'Ethique pour la Recherche en Imagerie Médicale" (CERIM) gave ethical approval for this research (number CRM-2001-051).

\section{Data availability}

All data produced in the present study are available upon reasonable request to the authors. 
medRxiv preprint doi: https://doi.org/10.1101/2022.01.28.22269989; this version posted January 30, 2022. The copyright holder for this preprint (which was not certified by peer review) is the author/funder, who has granted medRxiv a license to display the preprint in perpetuity.

It is made available under a CC-BY 4.0 International license.

\section{Figure and table legends}

Figure 1. Landmarks and pipeline of the deep learning model. (A) Illustration of the set of 33 landmarks; bilateral landmarks are named once; dotted lines show landmarks localized inside the skull; (B) 2-stage method used for model inference. SCN, SpatialConfiguration-Net; ROI, region of interest.

Figure 2. Localization and measurement error boxplots for automatic (green) and manual (orange) methods on $19 \mathrm{CT}$ scans from the test set. (A) Localization errors (mm) for each landmark; (B) Measurement errors $\left(\mathrm{mm} /{ }^{\circ}\right)$ for each cephalometric variable. For each pair of results, statistically significant differences are indicated $\left(* p<0.05 ;{ }^{* *} p<0.01 ;{ }^{* *} p<0.001\right)$.

Figure 3. Frontal, $3 / 4$ left and inferior views of the 3D models, reference (red) and predicted (blue) landmarks for 3 subjects. (A) Prognathic and asymmetric mandible; (B) retrognathic mandible; (C) craniofacial syndrome "outlier case", the errors in the predicted A point (at the level of the upper left canine apex) and the dental landmarks are to be noted.

Table 1. Mean radial errors $(\mathrm{mm})$, success detection rates $(\%(n))$ and minimum/maximum radial error $(\mathrm{mm})$ for each landmark on the hold-out test set without the outlier case $(n=37)$. MRE, mean radial error; SD, standard deviation; Min., minimum radial error; Max., maximum radial error; L, left; R, right.

Table 2. Mean errors $(\mathrm{mm})$ and success detection rates $(\%(n))$ for each cephalometric variable on the hold-out test set without the outlier case $(n=37)$. SD, standard deviation.

\section{References}

Alkhayer A, Piffkó J, Lippold C, Segatto E. 2020. Accuracy of virtual planning in orthognathic surgery: a systematic review. Head Face Med. 16(1):34.

American Academy of Oral and Maxillofacial Radiology. 2013. Clinical recommendations regarding use of cone beam computed tomography in orthodontics. Position statement by the American Academy of Oral and Maxillofacial Radiology. Oral Surg Oral Med Oral Pathol Oral Radiol. 116(2):238-257.

Bermejo E, Taniguchi K, Ogawa Y, Martos R, Valsecchi A, Mesejo P, Ibáñez O, Imaizumi K. 2021. Automatic landmark annotation in 3D surface scans of skulls: Methodological proposal and reliability study. Comput Methods Programs Biomed. 210:106380.

van Bunningen RH, Dijkstra PU, Dieters A, van der Meer WJ, Kuijpers-Jagtman AM, Ren Y. 2021 Aug 28. Precision of orthodontic cephalometric measurements on ultra low dose-low dose CBCT reconstructed cephalograms. Clin Oral Investig. [accessed 2021 Dec 22]. https://link.springer.com/10.1007/s00784-021-04127-9.

Chen R, Ma Y, Liu L, Chen N, Cui Z, Wei G, Wang W. 2022. Semi-supervised anatomical landmark 
medRxiv preprint doi: https://doi.org/10.1101/2022.01.28.22269989; this version posted January 30, 2022. The copyright holder for this preprint (which was not certified by peer review) is the author/funder, who has granted medRxiv a license to display the preprint in perpetuity.

It is made available under a CC-BY 4.0 International license.

detection via shape-regulated self-training. Neurocomputing. 471:335-345.

Chen X, Lian C, Deng HH, Kuang T, Lin H-Y, Xiao D, Gateno J, Shen D, Xia JJ, Yap P-T. 2021. Fast and Accurate Craniomaxillofacial Landmark Detection via 3D Faster R-CNN. IEEE Trans Med Imaging. 40(12):3867-3878.

Dot G, Rafflenbeul F, Arbotto M, Gajny L, Rouch P, Schouman T. 2020. Accuracy and reliability of automatic three-dimensional cephalometric landmarking. Int J Oral Maxillofac Surg. 49(10):1367-1378.

Dot G, Rafflenbeul F, Kerbrat A, Rouch P, Gajny L, Schouman T. 2021. Three-Dimensional Cephalometric Landmarking and Frankfort Horizontal Plane Construction: Reproducibility of Conventional and Novel Landmarks. J Clin Med. 10(22):5303.

Dot G, Schouman T, Dubois G, Rouch P, Gajny L. 2022 Jan 17. Fully automatic segmentation of craniomaxillofacial CT scans for computer-assisted orthognathic surgery planning using the nnU-Net framework. Eur Radiol. [accessed 2022 Jan 20]. https://doi.org/10.1007/s00330-02108455-y.

Gateno J, Xia JJ, Teichgraeber JF. 2011. New 3-Dimensional Cephalometric Analysis for Orthognathic Surgery. J Oral Maxillofac Surg. 69(3):606-622.

Gupta A, Kharbanda OP, Sardana V, Balachandran R, Sardana HK. 2016. Accuracy of 3D cephalometric measurements based on an automatic knowledge-based landmark detection algorithm. Int J Comput Assist Radiol Surg. 11(7):1297-1309.

Hao J, Liao W, Zhang YL, Peng J, Zhao Z, Chen Z, Zhou BW, Feng Y, Fang B, Liu ZZ, et al. 2021 Nov 1. Toward Clinically Applicable 3-Dimensional Tooth Segmentation via Deep Learning. J Dent Res.:002203452110404.

Hassan B, Nijkamp P, Verheij H, Tairie J, Vink C, van der Stelt P, van Beek H. 2013. Precision of identifying cephalometric landmarks with cone beam computed tomography in vivo. Eur J Orthod. 35(1):38-44.

ISO 5725-2:2019. Accuracy (trueness and precision) of measurement methods and results.

Kang SH, Jeon K, Kang S-H, Lee S-H. 2021. 3D cephalometric landmark detection by multiple stage deep reinforcement learning. Sci Rep. 11(1):17509.

Kapila SD, Nervina JM. 2015. CBCT in orthodontics: assessment of treatment outcomes and indications for its use. Dentomaxillofacial Radiol. 44(1):20140282.

Lang Y, Lian C, Xiao D, Deng H, Yuan P, Gateno J, Shen SGF, Alfi DM, Yap P-T, Xia JJ, et al. 2020. Automatic Localization of Landmarks in Craniomaxillofacial CBCT Images Using a Local Attention-Based Graph Convolution Network. In: Martel AL, Abolmaesumi P, Stoyanov D, Mateus D, Zuluaga MA, Zhou SK, Racoceanu D, Joskowicz L, editors. Medical Image Computing and Computer Assisted Intervention - MICCAI 2020. Vol. 12264. Cham: Springer International Publishing. (Lecture Notes in Computer Science). p. 817-826. [accessed 2021 Dec 22]. https://link.springer.com/10.1007/978-3-030-59719-1_79.

Lee SM, Kim HP, Jeon K, Lee S-H, Seo JK. 2019. Automatic 3D cephalometric annotation system using shadowed 2D image-based machine learning. Phys Med Biol. 64(5):055002.

Lim B-D, Choi D-S, Jang I, Cha B-K. 2019. Application of the foramina of the trigeminal nerve as landmarks for analysis of craniofacial morphology. Korean J Orthod. 49(5):326.

Liu Q, Deng H, Lian C, Chen Xiaoyang, Xiao D, Ma L, Chen Xu, Kuang T, Gateno J, Yap P-T, et al. 2021. SkullEngine: A Multi-stage CNN Framework for Collaborative CBCT Image Segmentation and Landmark Detection. In: Lian C, Cao X, Rekik I, Xu X, Yan P, editors. Machine Learning in Medical Imaging. Vol. 12966. Cham: Springer International Publishing. (Lecture Notes in Computer Science). p. 606-614. [accessed 2021 Dec 22]. https://link.springer.com/10.1007/978-3-03087589-3_62.

Ma Q, Kobayashi E, Fan B, Nakagawa K, Sakuma I, Masamune K, Suenaga H. 2020. Automatic 3D landmarking model using patch-based deep neural networks for CT image of oral and maxillofacial surgery. Int J Med Robot. 16(3). [accessed 2021 Dec 22]. https://onlinelibrary.wiley.com/doi/10.1002/rcs.2093.

Montúfar J, Romero M, Scougall-Vilchis RJ. 2018. Hybrid approach for automatic cephalometric 
medRxiv preprint doi: https://doi.org/10.1101/2022.01.28.22269989; this version posted January 30, 2022. The copyright holder for this preprint (which was not certified by peer review) is the author/funder, who has granted medRxiv a license to display the preprint in perpetuity.

It is made available under a CC-BY 4.0 International license .

landmark annotation on cone-beam computed tomography volumes. Am J Orthod Dentofacial Orthop. 154(1):140-150.

Naji P, Alsufyani NA, Lagravère MO. 2014. Reliability of anatomic structures as landmarks in threedimensional cephalometric analysis using CBCT. Angle Orthod. 84(5):762-772.

O'Neil AQ, Kascenas A, Henry J, Wyeth D, Shepherd M, Beveridge E, Clunie L, Sansom C, Šeduikytè E, Muir K, et al. 2019. Attaining Human-Level Performance with Atlas Location Autocontext for Anatomical Landmark Detection in 3D CT Data. In: Leal-Taixé L, Roth S, editors. Computer Vision - ECCV 2018 Workshops. Springer International Publishing. p. 470-484.

Payer C, Štern D, Bisch of H, Urschler M. 2019. Integrating spatial configuration into heatmap regression based CNNs for landmark localization. Med Image Anal. 54:207-219.

Pinheiro M, Ma X, Fagan MJ, McIntyre GT, Lin P, Sivamurthy G, Mossey PA. 2019. A 3D cephalometric protocol for the accurate quantification of the craniofacial symmetry and facial growth. J Biol Eng. 13(1):42.

Sam A, Currie K, Oh H, Flores-Mir C, Lagravére-Vich M. 2019. Reliability of different three-dimensional cephalometric landmarks in cone-beam computed tomography: A systematic review. Angle Orthod. 89(2):317-332.

Schwendicke F, Chaurasia A, Arsiwala L, Lee J-H, Elhennawy K, Jost-Brinkmann P-G, Demarco F, Krois J. 2021. Deep learning for cephalometric landmark detection: systematic review and metaanalysis. Clin Oral Investig. 25(7):4299-4309.

Schwendicke F, Singh T, Lee J-H, Gaudin R, Chaurasia A, Wiegand T, Uribe S, Krois J. 2021. Artificial intelligence in dental research: Checklist for authors, reviewers, readers. J Dent. 107:103610.

Sekuboyina A, Husseini ME, Bayat A, Löffler M, Liebl H, Li H, Tetteh G, Kukačka J, Payer C, Štern D, et al. 2021. VerSe: A Vertebrae labelling and segmentation benchmark for multi-detector CT images. Med Image Anal. 73:102166.

Torosdagli N, Liberton DK, Verma P, Sincan M, Lee JS, Bagci U. 2019. Deep Geodesic Learning for Segmentation and Anatomical Landmarking. IEEE Trans Med Imaging. 38(4):919-931.

Wang C-W, Huang C-T, Lee J-H, Li C-H, Chang S-W, Siao M-J, Lai T-M, Ibragimov B, Vrtovec T, Ronneberger $\mathrm{O}$, et al. 2016. A benchmark for comparison of dental radiography analysis algorithms. Med Image Anal. 31:63-76.

Wang H, Minnema J, Batenburg KJ, Forouzanfar T, Hu FJ, Wu G. 2021. Multiclass CBCT Image Segmentation for Orthodontics with Deep Learning. J Dent Res. 100(9):943-949.

Xia JJ, Gateno J, Teichgraeber JF. 2009. New Clinical Protocol to Evaluate Craniomaxillofacial Deformity and Plan Surgical Correction. J Oral Maxillofac Surg. 67(10):2093-2106.

Yun HS, Jang TJ, Lee SM, Lee S-H, Seo JK. 2020. Learning-based local-to-global landmark annotation for automatic 3D cephalometry. Phys Med Biol. 65(8):085018.

Zhang J, Liu M, Wang L, Chen S, Yuan P, Li J, Shen SG-F, Tang Z, Chen K-C, Xia JJ, et al. 2020. Contextguided fully convolutional networks for joint craniomaxillofacial bone segmentation and landmark digitization. Med Image Anal. 60:101621. 